\title{
The effect of memory color on form identification
}

\author{
R. P. MIAL, P. C. SMITH, M. E. DOHERTY, and O. W. SMITH \\ Bowling Green State University, Bowling Green, Ohio 43403
}

\begin{abstract}
Previous studies have demonstrated that a form's identity affects the phenomenal hue of that form. This effect has been attributed to the operation of the "memory color" phenomenon. The present study was proposed to assess the effect of "memory" or characteristic color on form identification. Results indicate that memory color, rather than interacting with the object in such a manner as to aid identification, induces a bias toward identification of an object of the memory color.
\end{abstract}

The present study was designed to determine the influence of "memory color" on the identification of form. The forms chosen for the study were common in $O$ 's environment and found in predominantly one natural hue.

The concept of memory color was first expressed by Hering (1964): "The color in which we have oftenest seen an external thing impresses itself indelibly on our memory and becomes a fixed characteristic of the memory image. What the layman calls the real color of a thing is a color which has become firmly attached to the thing in his memory: I might call it the memory color of the thing [p. 7]."

The empirical investigation of memory color began with a study by Duncker (1939). He reports that a green felt leaf in hidden red illumination maintains its greenness better than an identically colored felt donkey in the same illumination. This phenomenon is explained in terms of a compromise between "expectancy color"-the green of leaves-and the physical stimulation which was presented (the resultant of leaf green in hidden red illumination).

Duncker's study indicates that the identity of a form affects the reported color of that form. The question of whether the reverse is true, that memory color affects the identification of forms, has not been answered, however. Interest in the problem is at least as early as Helmholtz, who, in 1866, wrote that: "The connection of the instantaneous sensory impression with a conception developed by experience to which it is subordinated usually follows just as promptly and immediately as the sensation itself .... In many cases (especially with colours,.for instance) the conceptions of which we are speaking at present do not signify sensitive states of the subject but properties of the objects themselves. We see something white or red, bright or dark, etc., and the sensation becomes involved with the corresponding conception in such an insistent way that it is difficult to imagine the sensation apart from the association [1925, p. 596]." This statement implies that colors are important for us, not only as properties of objects, but also as means of identifying objects. The basic problem is whether an object's form is equally identifiable when presented in an unnatural color as when presented in a natural color.
Bruner and Postman's (1949) study is relevant to the above problem. Normal and trick (incongruous) playing cards were presented tachistoscopically until correct identification was reported. The incongruous cards were ones in which the color and suit were reversed, e.g., a black five of hearts. The recognition thresholds for the incongruous cards were significantly higher than for the normal cards. This can be interpreted in two manners: (a) the figures on an incongruous card were less identifiable, or (b) the figures may have been equally identifiable but, in the incongruous case, $O$ was hesitant to respond. The classical psychophysical method used by Bruner and Postman does not permit an independent evaluation of (a) or (b). Interpretation b implies the measurement of the O's sensitivity that is contaminated by his decision criterion; Interpretation a depends on the measurement of sensitivity alone.

The method of signal detection, as applied in the present study, allows a measurement of sensitivity, independent of the measurement of the decision criterion. Quantitative analyses of correct and incorrect responses to the stimuli presented provide measures of the O's sensitivity, P(A) (Green \& Swets, 1966), and response bias, $\mathrm{B}_{\mathrm{H}}^{\prime}($ Hodos, 1970).

\section{METHOD}

\section{Observers}

The Os were six undergraduate female students from Bowling Green State University. Participation in the experiment fulfilled a requirement of an introductory course in psychology and provided the students with extra credit. Each $O$ demonstrated normal color vision, as determined by the Ishihara tests prior to participation.

\section{Apparatus}

A Scientific Prototype Model GB tachistoscope was used. Luminance levels were $30 \mathrm{fL}$ for the stimulus channel and $23 \mathrm{fL}$ for the adaptation channel, as measured by a Model 1960pr Pritchard photometer, with a white card in place of the stimulus. Since the forms and their backgrounds were constructed of opaque paper, the stimuli were viewed by reflected light.

The stimulus forms were chosen such that they represented objects which were distinctive in contour, frequently encountered in $O$ 's environment, and highly associated with a "natural" color. These were: apple, policeman's cap, pear, and Christmas tree. Each form was cut from Munsell color papers corresponding as closely as the Munsell system allowed to: (a) the form's natural hue, hues (b) $180 \mathrm{deg}$ and (c) $90 \mathrm{deg}$ from 
Table 1

Specifications of Forms and Backgrounds

\begin{tabular}{|c|c|c|c|c|c|c|c|}
\hline Contour & Form Type & $\begin{array}{c}\text { Area of } \\
\text { Form }\left(\mathrm{cm}^{2}\right)\end{array}$ & $\begin{array}{l}\text { Natural } \\
\text { Hue }\end{array}$ & $180 \mathrm{Deg}$ & $90 \mathrm{Deg}$ & Gray & $\begin{array}{l}\text { Back- } \\
\text { ground }\end{array}$ \\
\hline & Apple & 1.40 & \multirow{3}{*}{$\begin{array}{l}2.5 \mathrm{R} \\
5 / 8\end{array}$} & \multirow{3}{*}{$\begin{array}{l}2.5 \mathrm{BG} \\
5 / 8\end{array}$} & \multirow{3}{*}{$\begin{array}{l}7.5 \mathrm{~PB} \\
5 / 8\end{array}$} & \multirow{3}{*}{ N5 } & \multirow{3}{*}{ N6.25 } \\
\hline & Alternate 1 & 1.44 & & & & & \\
\hline & Alternate 2 & 1.24 & & & & & \\
\hline & Policeman's Cap & .95 & \multirow{3}{*}{$\begin{array}{l}2.5 \mathrm{~PB} \\
5 / 6\end{array}$} & \multirow{3}{*}{$\begin{array}{l}2.5 \mathrm{Y} \\
5 / 6\end{array}$} & \multirow{3}{*}{$\begin{array}{l}7.5 \mathrm{G} \\
5 / 6\end{array}$} & \multirow{3}{*}{ N5 } & \multirow{3}{*}{ N6.25 } \\
\hline & Alternate 1 & .96 & & & & & \\
\hline & Alternate 2 & .81 & & & & & \\
\hline & Pear & .66 & \multirow{3}{*}{$\begin{array}{l}10 Y \\
7 / 6\end{array}$} & \multirow{3}{*}{$\begin{array}{l}5 R \\
7 / 6\end{array}$} & \multirow{3}{*}{$\begin{array}{l}10 \mathrm{~PB} \\
7 / 6\end{array}$} & \multirow{3}{*}{ N7 } & \multirow{3}{*}{ N8.25 } \\
\hline & Alternate 1 & .67 & & & & & \\
\hline & Alternate 2 & .66 & & & & & \\
\hline & Christmas Tree & .44 & \multirow{3}{*}{$\begin{array}{l}2.5 \mathrm{BG} \\
5 / 6\end{array}$} & \multirow{3}{*}{$\begin{array}{l}7.5 \mathrm{Y} \\
5 / 6\end{array}$} & & \multirow{3}{*}{ N5 } & \multirow{3}{*}{ N6.25 } \\
\hline & Alternate 1 & .53 & & & $2.5 \mathrm{R}$ & & \\
\hline 0 & Alternate 2 & .54 & & & $5 / 6$ & & \\
\hline
\end{tabular}

natural on the Munsell color wheel, and (d) gray. The three hues for each form were matched with respect to brightness and saturation. The gray form was matched for brightness. The ground for all forms and hues. was gray, a constant, to prevent the confounding of figure-ground contrast with identifiability. This control was suggested by the results of a study by Preston, Schwankl, and Tinker (1932), where brightness differences between symbol and background were found to alter the legibility of a symbol.

Two al ternate "nonsense" forms were constructed to match each of the four meaningful forms in every respect, with the exception of contour. Table 1 shows the contours of the meaningful forms and their alternates, along with size and hue specifications.

\section{Procedure}

$O$ was informed that her task was one of form identification and that she would be instructed as to what form type she was to identify (apple, pear, tree, or cap) prior to each series of trials. In addition to being told what she was to identify, $O$ always had next to her a white card on which the outline of the meaningful form and examples of alternate forms were drawn in black. This aspect of the procedure was implemented in order to insure that Os were aware of the form they were to identify. Merely stating that the form of a policeman's cap was to be identified is insufficient, as $O$ would not know whether the form was front, top, or side view. Examples of alternate forms (not the alternates actually used) were presented so that Os would be aware of the nature of the differences they would have to discriminate. Under the outlines were squares of each color in which the forms were to be presented. $O$ was told that the reason for presenting the forms in different colors could not be divulged, but since both the meaningful form and the alternates would be presented an equal number of times in each color, and since hers was a task of form identification, she should disregard color.

She was informed that the meaningful form would be presented $50 \%$ of the time, alternate forms the other $50 \%$, and that she was to respond "yes [ the meaningful form is present]," "yes-but unsure," "no-but unsure," or "no," depending upon her level of confidence. She was also asked to attempt to balance the number of responses in the yes and no categories. $O$ received 1 cent for correct "yes" or "no" responses and $1 / 2$ cent for correct "unsure" answers. For incorrect responses, the amounts were deducted. No feedback was given during the course of the trials.

$O$ then tachistoscopically viewed variations within one of the form types. A form type, e.g., apple, consists of each of the four hues of the meaningful form and each of the same four hues of the two alternate forms. Each form type was presented to each $O$ a total of 448 trials: 56 trials of each hue of the meaningful form $(4 \times 56=224)$, and 28 trials of each alternate form-hue combination $(2 \times 4 \times 28=224)$. Between trials, $O$ was exposed to a channel in the tachistoscope (adaptation channel), with a brightness comparable to that of the stimulus channel. The exposure duration ranged from 8 to $28 \mathrm{msec}$, depending upon the O-form combination.

The exposure duration was determined for each $\mathrm{O}$ during a series of warm-up trials occurring prior to each series of trials with a new form type and at the beginning of each day's observations. The warm-up consisted of as many trials as were necessary (approximately 30 ) for the $E$ to determine an exposure duration allowing the desired ratio of correct responses to incorrect responses (a ratio of .6 was sought in order to optimize the statistical technique, but any performance of approximately .5 to .7 was accepted). The forms used during the warm-up were those used for the succeeding trials.

The 448 trials for a form type were presented randomly during four sessions of 112 trials. All observations on a form type were completed within $70 \mathrm{~min}$, including 5 -min rest intervals between sessions. Observations for all four form types were completed within a 9-day period.

\section{RESULTS AND DISCUSSION}

Receiver operatirg characteristic (ROC) curves were calculated on the basis of individual hit and false alarm 
rates (Green \& Swets, 1966, p. 42). A "hit" consists of $O$ 's correctly reporting that the meaningful form was present, while a "false alarm" is an incorrect meaningful form-present response. The rating procedure utilized by the Os permitted a three-point ROC curve to be determined. If presenting a form in its natural color increases the probability of correct identification of that form, then the hit rate (HR) and the $P(A)$ for form, natural hue, should be greater than the HR and $\mathrm{P}(\mathrm{A})$ for form, unnatural hue.

The HR across Os for natural hue was .62; for $180 \mathrm{deg}$ from natural, .56; for $90 \mathrm{deg}$ from natural, .61; and for gray, .56. A t test of the difference between $H_{\mathrm{R}}$ nat and $\mathrm{HR}_{\text {unnat }}$ is significant $(\mathrm{t}=1.94, \mathrm{df}=92, \mathrm{p}<.05)$. The HR measure is confounded by O's decision criterion, however, just as classically determined thresholds are. Therefore, $P(A)$ is in this case the measure of importance. Contrary to the hypothesis, Os' overall sensitivity to form was not affected by color. P(A)s across Os for natural hue, 180 and $90 \mathrm{deg}$ from natural hue, and gray, were $.60, .61, .60$, and .60 , respectively. Analysis of false alarm rates (FARs) will demonstrate why. In the computation of $\mathrm{P}(\mathrm{A})$, a high FAR will compensate for a high HR, as will a low FAR for a low HR. FAR across Os for natural hue was .47 , while for 180 and 90 deg from natural and for gray, FARs were $.38, .45$, and .41 , respectively. Again, the difference between $F A R_{\text {nat }}$ and $F A R_{\text {unnat }}$ is significant $(t=2.38$, $\mathrm{df}=92, \mathrm{p}<.01)$. Thus, rather than causing an increase in sensitivity to form, natural hue caused a tendency for Os to respond "yes." This tendency is reflected by Hodos' index of response bias, $\mathbf{B}_{\mathrm{H}}{ }_{\mathrm{H}}$, which demonstrated a difference in bias of $21.4 \%,-20.7 \%$ for natural hue and $+0.7 \%$ for unnatural hue. Virtually all of the bias was due to hues which were in these cases memory colors. Although Os were instructed and paid to utilize form as the sole criterion, they were unable to disregard color, and did, in fact, use color as a secondary criterion.

In summary, the data allow two conclusions. First, with the objects' form serving as the criterion for discrimination, the addition of memory color did not alter the perceived nature of the forms in such a manner as to affect discriminability. Secondly, memory color induced a response bias, often causing Os to make a response signifying the presence of the object of the memory color, when only the memory color and not the object was present. It is important to note that, at present, these conclusions are limited to brief exposure situations.

\section{REFERENCES}

Bruner, J. S., \& Postman, L. On the perception of incongruity: A paradigm. Journal of Perso nality, 1949, 18, 206-223.

Duncker, $K$. The influence of past experiences upon perceptual properties. American Journal of Psychology, 1939, 52, 255-265.

Green, D. M., \& Swets, J. A. Signal detection theory and psychophysics, New York: Wiley, 1966.

Helm holtz, H. v. Physiological optics. (Trans. J. P. C. Southall from 3rd German ed., 1866.) New York: Dover, 1925.

Hering, E. Outlines of a theory of the light sense. (Trans. L. M. Hurvich and D. Jameson.) Cambridge, Mass: Harvard University Press, 1964.

Hodos, W. A nonparametric index of response bias for use in detection and recognition experiments. Psychological Bulletin, $1970,74,351-354$.

Preston, K., Schwank1, H., \& Tinker, M. A. The effect of variations in color of print and background on legibility. Journal of General Psychology, 1932, 5, 459-461.

(Received for publication August 27, 1973; revision received November 14,1973 ; accepted December 27,1973 .) 